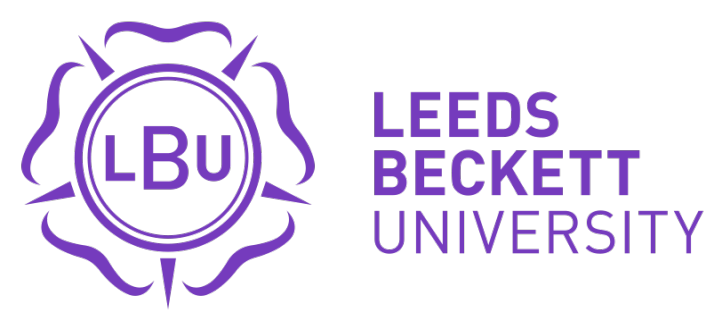

Citation:

Lamond, I and Agar, L (2019) Beyond the frame: Use of augmented screenings as a visual methodology in critical event studies. Events Management, 23 (2). pp. 269-278. ISSN 1943-4308 DOI: https://doi.org/10.3727/152599518X15403853721213

Link to Leeds Beckett Repository record:

https://eprints.leedsbeckett.ac.uk/id/eprint/5332/

Document Version:

Article (Accepted Version)

The aim of the Leeds Beckett Repository is to provide open access to our research, as required by funder policies and permitted by publishers and copyright law.

The Leeds Beckett repository holds a wide range of publications, each of which has been checked for copyright and the relevant embargo period has been applied by the Research Services team.

We operate on a standard take-down policy. If you are the author or publisher of an output and you would like it removed from the repository, please contact us and we will investigate on a case-by-case basis.

Each thesis in the repository has been cleared where necessary by the author for third party copyright. If you would like a thesis to be removed from the repository or believe there is an issue with copyright, please contact us on openaccess@leedsbeckett.ac.uk and we will investigate on a case-by-case basis. 


\section{Beyond the frame: Use of augmented screenings as a visual methodology in critical event studies.}

Lamond, I.; Agar, L.

\section{Abstract}

Disrupt is an ongoing project exploring methodologies appropriate to critical perspectives in event studies, suitable for researching activism, protest, and events of dissent. This paper considers the use of augmented film screenings, which combine cinematic presentation with non-film/live elements and panel-led discussions, as one of the approaches trialled as part of the project. Rooted in techniques based in photo and video elicitation, whilst incorporating aspects of the use of film to educate, stimulate and provoke radical debate, employed by Latin American activists since the 1960s, the augmented screening approach explored in this paper formulates an innovative approach in evental visual research methodology. Going further than photo and video elicitation, it combined film with live disruptive elements in the attendee experience to legitimise participant engagement with narratives that challenge the dominant hegemonic discourses in which we act and interact. In conclusion we consider some of the limitations and opportunities of evental research methods that use film as a key element within a framework anchored in a visual elicitation approach.

\section{Key words}

Photo-elicitation; Video-elicitation; Evental research; Protest; Critical event studies. 


\section{Introduction}

Research undertaken between 1979 and 2015, as part of the Global Database of Events, Language and Tone (GDELT) project, suggests that the early part of this century has seen a marked increase in participation in public acts of protest and dissent (GDELT 2015). GDELT used a complex network of English language news feeds, from across multiple media platforms, to globally map protest events. The purpose of the Disrupt research project, which began in late 2016, was much more subtle. Using critical event studies (CES) as a conceptual starting point, its principal aim was to explore methodologies that could be used to obtain a richer, and more qualitative, understanding of how events of dissent animate urban spaces, from a more localised perspective. In doing so, it set out to trial several research approaches that could develop knowledge around the study of eventful protest (Della Porta 2008), from the bottom-up. This paper focuses on one components of that project.

The project held six cinematic screenings between November 2016 and October 2017; each event combined a programme of mainly documentary film with the use of popup venues and various elements of what Atkinson and Kennedy (2016) refer to as 'live cinema'. The aim of our paper is to discuss that methodology, share how it was deployed, and consider its evolution over the duration of the project. Following a consideration of its preliminary findings we will discuss the limitations and opportunities such a research approach offers.

It is important to recognise that events of dissent do not fit comfortably into the standard frames of reference employed in events research. In their work on protest as leisure Lamond and Spracklen $(2015,2016)$ suggest that events of dissent require a 
more diverse approach to methodology than currently found in much mainstream event management scholarship. Because of the intrinsic disruptive character of protest some of the outcomes and impacts associated with participation can be assumed to be personal and reflexive. As such they articulate behaviours and interactions, including structures of trust, that mean they may not be straightforwardly apprehended through more traditional approaches to social scientific research. Events that either express, or result in changes to, an individual's world view (Kaal et al 2014), or meaning making (Stanley 2012), may be more fruitfully investigated using a richer mix of methodologies than research in the field of events commonly employs. To address this Lamond (forthcoming) has argued that the process of research, within CES, should become more evental (i.e. it should exhibit characteristics of contestation and disruption), and thus enable new ways of developing an understanding of the discourses at work to come to the fore. However, to do that we need to first establish how CES differs from mainstream inquiry in events, and what we propose constitutes evental research.

\section{CES and Evental Research}

\section{What is CES?}

Recently CES has emerged as a critical approach to the study of events that has grown both from a broad-spectrum frustration with the events curriculum (Moufakkir and Perneky, 2014), and a reaction against the dominant cultural-political economy of neo-liberalism that haunts our understanding of the referent of 'event' (Lamond and Spracklen, 2015). CES draws on a variety of socio-cultural and philosophical trajectories. These include those associated with critical theory; notably the analysis of the culture industry developed by Adorno (2005), Habermas' idea of the public 
sphere (especially his discussions around communicative relationships and the colonisation of the lifeworld (2006)), and, significantly, in how those ideas are applied to critical approaches in leisure and cultural studies (see, for example, Spracklen 2013; McGuigan 1996). However, it is neither merely the application of critical theory to the study of events, nor is it simply the widening of event studies to incorporate a greater interest in the sociological context in which events occur; as we find in the work of Maurice Roche (2017) and Chris Rojek (2013). Crucially CES develops from a radical problematisation of the referent of 'event'.

The conceptual foundations of CES as an orientation bear a close affinity to how 'event' is used in the work of Slavoj Žižek (2014) and Allain Badiou (2003, 2013). Both construe event as rupture. For Žižek rupture is a breakdown of the Imaginaries produced and reproduced by ideology, thereby enabling an apprehension of the Real (understood as that which cannot be grasped by, or articulated through, any discourse): 'event' is thus encountered as disparity (Žižek 2016).

Following Foucault (1986), CES takes the space in which rupture occurs to be complex and layered; produced and reproduced through multiple socio-cultural relationships, a heterotopic domain where diverse discourses operate to construct the ontologies we encounter in our daily actions and interactions with others. Space becomes multiple, a palimpsest that undergoes continuous processes of inscription, erasure and reinscription. That multiplicity keys into CES's connection to Badiou, in that the essential contestation and disruption that lies at the heart of the 'event' is not solely one where a Real can be apprehended, rather it is where multiple possibilities arise (Badiou 2007). Not only does disruption (rupture) expose discourses that are at work within a dominant cultural political economy, it brings to the fore the articulations of power that 
endeavour to address the breach, whilst presenting us with alternatives; possibilities of resistance, resilience and creation (Spracklen and Lamond 2016). The multiplicities of possibility, combined with those of space, result in the referent of 'event' becoming a multiplicity of multiplicities; it is that which gives 'event' the characteristic of contestation that CES attributes to it. Consequently, what event management constructs as its locus, the singular 'event', becomes understood as a discursive artefact produced to facilitate its commodification and monetisation. In place of that, CES construes 'event' as a liminoid (Turner 1974) space of possibility and potentiality, consequently it is less an event and more a site (a time/space) that should be construed as evental.

\section{Evental research}

In place of seeking out a single narrative CES endeavours to grasp any 'event' by actively seeking out its multiplicity; i.e. how it disrupts, and the character of its contestation. It is that fascination with contestation that CES endeavours to explore and articulate, appreciating the value of diversity in the articulation of the imaginary that becomes associated with the 'event', and ascertaining how, by whom, and under what discursive regimes of power that disruption is channelled, contained, directed and/or mitigated. As such it offers a counterpoint to the application of functionalist reason (Habermas 2006) in the study of events, which has an instrumentalising and commoditising effect on 'planned events' (Getz 2016), concretising them into primarily economic artefacts. In contrast, participation in events of dissent and protest present us with complexity and fluidity; where the spatial-temporal multiplicities of the evental interlace with those of the identity and self-othering of the participant (Spracklen and Lamond 2016). Methods, whether they be predominantly qualitative, quantitative, or mixed, that are grounded in a more rigid methodological framework, would struggle to 
apprehend this. Alternatively, any approach that respects the fluidity of 'events', whilst adopting an ontic orientation that emerges out of such fluidity itself, would seem to be

a better fit. To attain that, it becomes necessary for the process of research itself to exhibit characteristics of disruption and contestation; i.e., it must become more evental.

Reflecting on this, the Disrupt project trialled a variety of participatory and co-creative research approaches; this paper focuses on one, the incorporation of augmented film screenings as a method. However, the adjective 'augmented' requires elaboration, as its referent is not immediately apparent. For the project, an 'augmented screening' refers to a combination of cinematic presentation, some form of post-screen discussion (though not, necessarily, about the film(s) shown), and other non-film elements (participatory or experiential) that are thematically linked to the film(s) presented. To grasp the foundations of the approach requires consideration of two literatures. The first concerns the use of image (whether photographic or video) as a data elicitation technique, the second addresses the event of screening through a consideration of what has become known as Live or Third Cinema.

\section{Film and Research: from elicitation techniques to unique film screenings}

Photo and video/film-based elicitation techniques have a substantial history in the social sciences, both as a source of data and as a stimulus for data capture (Jewitt 2012). Whilst the use of film screenings in the Disrupt project had an affinity with other visual methodologies, it differed from them in that non-image-based elements were also incorporated. However, because of its connection to photo and video elicitation, a consideration of the literature associated with them is appropriate. 
Howard Becker (1974) argues that sociology, as a distinct disciplinary field (dated from August Comte's introduction of the term) and the emergence of photography, through Louis Daguerre's invention of the process, share the same year of birth, and that from the start those two areas of human activity collaborated. It was, however, the visual anthropologist John Collier that was the first to propose using photography as a means of eliciting data from interview participants (Collier 1967), referring to this technique as photo elicitation (PE). Harper (2002) defines his approach as "...the simple idea of inserting a photograph into a research interview" (p. 13), going on to argue that "(t)he difference between interviews using images and text, and interviews using words alone lies in the ways we respond to these two forms of symbolic representation" ( $p$. 13). Whilst van Auken et al (2010) suggest that participant created images provide a useful stimulus for discussion, Cederholm (2011) maintains that PE should be integrated into the life-world of participants, and not simply used as a conversational 'can-opener'. In her work on backpacker tourism (Cederholm 2004) she found that the use of photographs can elicit "...both subjective emotions, thoughts and reflections, as well as patterns of (the) cultural and social constructions of reality" (p. 240). This is supported by Richard and Lahman (2015) whose use of PE in research around literacy found that it could elicit, in their terms, "emotional and cognitive information...brought forth through visual metaphor" (p.4). Clark-Ibanez (2004) suggests that the use of PE, in an interview setting, can ease rapport between participant and interviewer, while Pachmayer et al (2017) also argue that the use of images can enhance memory through the recollection of finer detail.

In a recent paper Harper (2016) takes the reader on his personal journey in visual sociology. In that piece he suggests that photography contributes to sociological 
inquiry through two principal approaches. The first draws data from photographic documentation that has been instigated by the investigator, whilst the second considers the pre-existing image as its source material; both sources offering a window of opportunity to apprehend society and the social. As a technique this gives weight to the efficacy of the image in facilitating conversation and discussion with research participants; in that, there is considerable overlap with video elicitation (VE).

In his discussion of the integration of ethnographic research and film making Erik van Maaker (2000) describes VE as an approach that “...can serve as a common point of reference for the anthropologist and participants, and thus allows for the elicitation of the latter's ideas and perceptions" (p. 185). Jewitt (2012) suggests that, in addition to the use of film making in field work, there are four ways of using video in research. The first, participatory video, being a form of action research where participants are given access to video equipment and training so that they can document an aspect of their life; its underlying aim is, as Jenkins puts it, “...to reduce the gap between the concepts and models of researchers and those of individuals and communities" (p.3). As an approach, the film product, as output, is the documentation of a theme or topic initiated by questions originating with the researcher, rather than the participant, even when it is the participant that has captured the video material. In contrast videography uses film as a means of gathering non-verbal data that can then be used to stimulate critical reflection. Whilst aligned to the participatory video, it focuses on giving more power to the research participant to confront the narrative gaze of the researcher. These are consistent with the first approach to PE suggested by Harper (2016).

Use of existing video material, the third route, is more closely associated with Harpers second approach to the use of the image, in that it is concerned with repurposing. The 
film's content becomes reframed as documentation of the social practices of the time in which the film was made, providing the research with a gateway to prior sociocultural relations and forms of interaction. Finally, she argues, film can be "...used alongside interviews or focus groups to prompt discussion, stimulate recall or provide a basis for reflection" (p. 3). Such a perspective resonates with the claims made for PE by Pachmayer et al (2017).

But Disrupt did not solely rely on film, it also considered the screening space an evental site; consequently, the unique cinematic presentations were also framed as live events. The creation of live events around a unique film screening, or, in our terms, the 'augmentation' of those screenings, has become a subject of interest for researchers in some parts of the film exhibition sector (Brook et al, 2016). In the period that the Disrupt project was being planned, researchers at the first Live Cinema conference argued for a distinction between specialist experiential settings for film watching and what is often called 'event' cinema. These two areas of cultural production are frequently discussed together as novel sources of cinema content, with the latter category usually implying that the screened content is live. The term Event Cinema referring to the broadcast of live events, such as theatre, opera, and sports, into traditional cinema venues and arts centres. Atkinson and Kennedy (2016) define Live Cinema as:

"...a cinema that escapes beyond the boundaries of the auditorium whereby film screenings are augmented by synchronous live performance, site-specific locations, technological intervention, social media engagement, and all manner of simultaneous interactive moments including singing, dancing, eating, drinking and smelling" (p. 139). 
Whilst elements of their definition can be applied to the screenings organised for the Disrupt project, Live Cinema UK's perspective (livecinema.org.uk ND) is more focused on identifying its commercial and entertainment value. That was not the purpose of the Disrupt project. Instead, it aimed to engage a public through the augmentation of unique film screenings, thereby forming an evental site so that a discursive setting, whose thematic orientation was steered by the moving image, could be facilitated.

'Augmented' cinema experiences are not radically new, they have a long history. Films with political subject matter and messages have been screened in ways intended to engage and interact with an audience since at least the 1960s. In an area of film culture often referred to as 'third cinema' (Solanas and Getino, 1969), screenings were used to incite action and debate, working as an educational tool to aid the development of a revolutionary consciousness. This practice emerged from a genre of Latin American radical film making, where films were made to be the 'detonator' of discussion (Presence 2013). Screening practices associated with third cinema have tended to emphasise the use of non-traditional spaces, taking films directly into the marginalised or oppressed communities that they are intended to inspire. This is not to suggest that the Disrupt researchers believed that the screenings in Leeds constituted a form of revolutionary education in West Yorkshire. However, as with 'third cinema', the organisers motivation was to incite reflection and conversation... it was certainly not commercial.

\section{The Disrupt Project}


Disrupt was a twelve-month collaborative research project, organised by academics from across three schools at Leeds Beckett University, and financed as part of an internal research cluster award. The project comprised several methodological approaches; these included surveys, focus groups, interviews, and a variety of site specific interventions in the public realm (such as a programme of guided walks); they are not the focus of this paper. Here, our objective is to discuss, in detail, the use Disrupt made of augmented film screenings as a visual methodology.

The plan to incorporate live cinema elements as a contribution to the project occurred early in the planning phase, prior to the project commencing. However, those film screenings did not follow a pre-set format; instead it formed an organic, and somewhat anarchic, element which meant that revisions to the mode of presentation of the films could be made as the programme progressed. Whilst the cinematic presentations exhibited a family resemblance which maintained their connection to the research agenda, their fluidity proffered a level of autonomy that encouraged critical reflexivity within the programme, allowing for greater collaboration with activist groups and cultural producers. By refraining from the imposition of a set of values or ideals around the screening format the instances of these 'events' could be more responsive to the publics that engaged with them. The capacity to adapt and reflect after each iteration was particularly helpful in that it meant those involved could rethink and rework their approach to the screenings as the series progressed.

Prior to the research commencing, the principal investigator organised several meetings to lay the groundwork with key external partnerships. Researchers from the Leeds Beckett University and representatives from various social movements based in the region were brought together to talk through ideas about which films to include. 
Further meetings were held to establish links with the cultural organisations that could present the films at a local level. This latter element was essential for drawing on a skill set that included how to source the films; obtain permission to publicly screen them; identify suitable spaces in which they could be shown and establish how audiences could be reached. The discussion around which films should be screened drew on expertise from activists associated with LGBT rights, migration, combatting food waste, anti-war movements, and environmental campaigning. As well as establishing connections with social movements the project entered into a partnership with the Leeds International Film Festival (LIFF), during the preparation for the festival's edition in 2016, and contacted the city's leading independent cinema, The Hyde Park Picture House. Through those connections, they also developed a strong collaborative link with an independent film programmer experienced in showing documentary films in non-traditional venues.

Film screenings were to be followed by a panel discussion, involving activists associated with the film's theme, that focused on issues raised by the film, rather than the films themselves. Additionally, the events included other, less familiar, elements. As such, the augmented films provided a catalyst to disrupt and provoke a reaction from their associated panel and audience.

Operationally, the choice of panellists for the post-screening discussion were finalised in the period between one film and the another, whilst the 'live cinema' elements would be negotiated between the principal investigator, the collaborative partners and the host venue. A focus on themes over precise content, meant the meanings that the films evoked in participants (both on the panel and in the audience) were given a prominence in the discussion. 
Whilst the film was thought to be the primary reason for audience attendance, the events fulfilled a plural agenda for the project. As well as a source of capturing baseline data they were also a means of recruiting self-selected research participants/respondents for a later interview phase. The live cinema/third cinema format forming an experiential frame of references facilitating rapport, and a pool of shared memories, that could be used to elicit the production of data at those interviews (Clark-lbanez, 2004, and Pachmayer et al, 2017). Consequently, a code of research ethics was applied to the event design: each audience member was offered an optional survey card that included information about the project, basic consent details, and some simple questions. In addition, each screening began with an announcement about photography, voice recording and audience participation.

The decision of which films to screen, where, and how the events were to be arranged and promoted to the public, were made in collaboration with project's Leeds-based cultural intermediary partners. Pragmatically, it made sense to hold the first public film event during the film festival: as LIFF was celebrating its $30^{\text {th }}$ anniversary the marketing campaign surrounding it had increased its already strong presence in the cultural calendar of the city. However, the films intended to open the project were filtered through that partnership, due to the festival's pre-exisiting conditions and criteria. Ultimately, the Disrupt team's choices were considered but, after some negotiation, supplanted with two films suggested by LIFF's lead programmer. Despite that, the films screened were consistent with the project's research objectives and were approved by its activist partners. Inclusion in the official festival programme meant that the project benefited from a far wider reach than otherwise would have been possible. Live elements were then added. Following the screening of the first 
film, 'Noviembre' ('November', 2003), the audience were treated to Leeds Community Choir performing protest songs from around the world, on the steps of the Leeds Town Hall. The second film, Les Sauteurs ('Those Who Jump', 2016), was shown in a smaller room at the same venue. It was followed by a lengthy discussion and an impromptu reading by one of the panellists that had a specialist research interests in migrant experiences.

In February 2017, billed as part of LGBT History Month, a compilation of short films under the heading 'Out and About in Shorts' was shown at the Hyde Park Picture House. All the selected films explored points at which society, sexuality, gender and activism intersect; they included 'All Out! Dancing in Dulais' (1986), which documented the alliance formed between a group of young homosexuals from London and miners in Dulais Valley during the miners' strike of 1984-1985, and 'Slap!' (2014), an exploration of teenage masculinity through a drama about a young boxer who secretly likes to cross-dress. The other films shown were: 'Venus' (2016); 'Alphabet Club' (2014), and 'Video 28' (1986). Those screenings included a book signing by one of the panellists, who's LGBT activism is articulated through their work as a multi-media artist.

In March, the Canadian documentary 'Just Eat It!' (2014) was shown at the Sheaf Street Cafeteria, in Leeds City Centre. It follows a couple who pledge to eat only discarded food for 6 months. The event was organised in conjunction with the Real Junk Food Project (RJFP) who have achieved national recognition for their efforts to divert edible waste food from landfill sites and serve it on a Pay As You Feel basis in cafés. That evening included a buffet of re-purposed food prepared by the RJFP, audience donations raising a considerable amount of money for that project. A 
representative of the RJFP's Fuel for Schools campaign and a member of the Leeds Permaculture network formed the panel.

In April we screened 'We Are Many' (2014). That film documents the global protest event of February 15th, 2003, when millions, in location from around the world, marched against the impending invasion of Iraq. That screening was augmented through a banner making workshop, and by a live exhibition of protest banners, arranged with Leeds vocal collective The Commoners Choir, who, before the film began, sang as they paraded - banners in hand - around the audience.

Wharf Chambers was the venue for our screening in October 2017. The venue it is better known for live music, and to gain access to the space in which the films were to be shown the audience needed to pass through one attending a rock band's gig. Our event was composed of a series of short documentaries created by the guerrilla/activist film cooperative 'Reel News'. Themes covered included, the constitutional crisis in Spain, following Catalonia's declaration of independence; a cleaners' strike at SOAS, and the current campaign against Cuadrilla undertaking exploratory work around fracking in West Lancashire.

In most cases the screening was the first time many panellists had seen the film(s) presented; this produced novel dynamics in terms of the differing responses those contributors had to the material presented. Finally, the live cinema elements, which were intended to take both panellists and audience by surprise, added a level of disruption to an otherwise straightforward film presentation. It was through the augmentation of the screenings that the space became inscribed as a site of evental research. By combining visual and disruptive elements a liminoid space was opened 
up, where attendees/participants felt empowered to discuss themes made permissible by the multiplicity of the evental moment in which they were placed.

The voluntary postcard survey, left on every seat, included some basic demographic data, a closed set of questions about the ways participants did, or didn't, engage in acts of protest, and one open question about what protest meant to them. Finally, it asked participants if they were happy to be interviewed in a later phase of the project and, if so, to leave some contact details. At the time of writing these interviews are yet to take place.

\section{Augmented screenings as a visual methodology}

It was, however, the augmented screenings, and not the on-seat survey, which formed the cornerstone of the visual methodology Disrupt trialled. The augmentation constituting, as we have referred to it, a more evental approach to research through a combination of unique screening with Live Cinema/Third Cinema elements to disrupt the attendee experience. The visual element of the methodology resonating with Jewitt's (2012) formulations of video elicitation as that which can be "...used alongside interviews or focus groups to prompt discussion, stimulate recall or provide a basis for reflection" (p. 3). Certainly, the disrupted screenings had an observable impact on the reactions and interactions of those present. From the anecdotal accounts of members of the research team present, there was a much higher level of interaction between people who did not appear to be previously acquainted, and a lot more laughter, than is commonly encountered at unique screenings which incorporate a panel discussion. By drawing together discussants who were also unfamiliar with the film(s) they followed, placing them in an analogous relationship to the presentation as the 
audience, prompted reactions and responses that a straight screening/Q\&A would not have brought to light. In this respect they diverged from the position of Kwasnicak et al (2015) hold on the use of VE, as they were not used to elicit memories of the events depicted. Using an augmented film approach inscribed the venues as an evental space where potentialities and possibilities could be considered, and differences discussed in an environment of sensitivity and safety. Consequently, they resonated more with Richards and Lahman's (2015) suggestion that visual methods bring forth "emotional and cognitive information...through visual metaphor" (p.4), the themes and issues evoked by the image inciting a response and not solely eliciting one. Whilst the transcripts of the post-screening discussions are yet to be analysed, the discussions themselves were lively and diverse, providing an interesting source of data concerning individual narratives of motivation around engagement with events of dissent. This would seem to suggest that, following van Auken et al (2010), this visual method facilitated the production of something closer to a visualising community.

With the interview phase of the project yet to commence, it will also be of interest to establish whether the evental framing around the use of an image-based tools further enhances memory, as the work of Pachmayer et al (2017) might suggest.

The Disrupt project is still at an early stage and we cannot yet ascertain whether the trial of the evental/visual methodology was successful. It could be argued that the act of simply attending the presentation of a film, in many cultures and communities, has become routine. Given the baseline demographic profile of the population drawn to the screenings, the film presentations may not have been, in themselves, a sufficient stimulus. However, the inclusion of evental/augmentation elements did make them more immersive for attendees, and it is that was at the heart of the projects trial. With 
the interview phase ahead of us, we hope to obtain more detailed information about the advantages and limitations of using such augmented/evental screening as a visual methodology. Our initial impression is that bringing together visual media with elements that disrupt the routine experience of watching film can both enhance rapport between researcher and participant and support shared learning. To that extent we found its value was consistent with the use of film in Third Cinema; that is, as a pedagogical tool that can incite discussion and enable the co-creation of learning.

\section{Conclusion}

In conclusion some acknowledgement of the problems of employing such visual methods is necessary. Whilst augmented screenings may prove to be of value to researchers interested in the study of events of dissent there are some practical concerns that mean its deployment can prove challenging. The cost of such ventures is significant. Alongside film and venue hire there are the fees of the panel members, many of whom will participate as an element of their activist practice and will want their cause, if not themselves, remunerating for their participation. Also, depending on the form the augmentation takes, this can also be costly; a cost that is not just financial. The detailed negotiations that necessarily follow an attempt to draw together diverse organisations into some form of short-term partnering relationship, especially in instances where there is no clear financial gain for one or more of those parties can be problematic, stressful, and very time consuming. As a research team we found this particularly challenging when some elements in the partnership we were endeavouring to establish either had a strong historical identity, or a clearly defined reputational identity, that did not smoothly dove-tail with that of other elements of the short-term relationship that the project required. 
Overall augmented/evental screenings work as a form of visual methodology within an approach that adopts a critical orientation to the study of events. In answer to the question - does such an approach work? It is too early to say their success is a resounding, Yes. However, whilst an appropriate response would be more tentative, it is certainly not a, No. An evental approach to research that incorporates augmented screenings demands time, resources and finance. Its success requires the formation of strong partnerships and a need for flexibility from all those drawn into establishing its programme and its delivery.

Disrupt began as a project whose aim was to explore innovative methods in the study of events of dissent from the bottom-up, whilst that is still ongoing it has set the foundations for its own future development and prepared the ground for future research collaborations. The partnerships established by the research team will endure; further ventures are already being planned that will extend the reach of using augmented screenings in forthcoming projects, whilst some future funding applications by research team members are set to incorporate elements of the methodology. Disrupt is now moving on to a quieter stage, one that concentrates on interviews, transcription, detailed text analysis and the testing of hypotheses around the success of the approaches it has trialled. That stage, however, would neither be as fruitful as it appears, nor as diverse, if it had not been for the incorporation of augmented/evental screenings as a visual methodology. 


\section{$\underline{\text { Acknowledgment }}$}

Funding for this phase of the Disrupt project was provided as part of a research cluster award granted by Leeds Beckett University.

\section{References}

Adorno, T. (2005). The Culture Industry. Trans. J.M. Bernstein. Abingdon:

Routledge.

Atkinson, S. A., \& Kennedy, H. W. (2016). Inside-the-scenes: The rise of experiential cinema. The Journal of Audience and Reception Studies. 13(1), 139-151.

Badiou, A. (2003). Saint Paul: The Foundations of Universalism. Stanford: Stanford University Press.

Badiou, A. (2007). Being and Event. London: Continuum.

Badiou, A. (2013). Philosophy and the Event. Cambridge: Polity Press.

Becker, H.S. (1974) Photography and sociology. Studies in Visual Communication, 1(1), 3-26.

Brook, L., Atkinson, S. and Kennedy, H.W. (2016). Live Cinema in the UK Report 2016. London: Arts Council England.

Cederholm, E.A. (2004) The use of photo-elicitation in tourism research-framing the backpacker experience. Scandinavian Journal of Hospitality and Tourism, 4(3), 225241. 
Cederholm, E.A. (2011) Photo-elicitation and the construction of tourist experiences. In T. Rakic and D. Chambers (Eds) An Introduction to Visual Research Methods in Tourism. pp.92-107

Clark-Ibanez, M. (2004) Framing the social world with photo-elicitation interviews. American Behavioural Scientist. 47 (12), 1507-1527

Della Porta, D., (2008). Eventful protest, global conflicts. Distinktion: Scandinavian Journal of Social Theory, 9(2), 27-56.

Collier, J. (1967) Visual Anthropology: Photography as a Research Method. New York: Holt, Rinehart and Winston.

Foucault, M. (1986). Of other spaces. Trans. J. Miskowiec. Diacritics 16(1), 22-7 GDELT (2015). Online: https://blog.gdeltproject.org/mapping-global-protests-redux/ Retrieved $1^{\text {st }}$ November 2017.

Getz, D. (2016). Event Studies: Theory, Research and Policy for Planned Events. Abingdon: Routledge.

Grierson, J. (1966). Grierson on Documentary. Ed. F. Hardy. Los Angeles: University of California Press.

Habermas, J. (2006). The Theory of Communicative Action: The Critique of Functionalist Reason. Cambridge: Polity Press.

Harper, D. (2002) Talking about pictures: A case for photo elicitation. Visual Studies. $17(1), 13-26$

Harper, D., 2016. The Development of Visual Sociology: A view from the inside. SocietàMutamentoPolitica. 7(14), 237-250 Jewitt, C. (2012) An introduction to using video for research. National Centre for Research Methods Working Paper 03/12. NCRM and ESRC Kaal, B., Maks, I., van Elfrinkhof, A. (Eds) (2014). From Text to Political Positions: Text Analysis Across Disciplines. Amsterdam: John Benjamins Publishing Company. 
Kwasnicak, D.; Dombrowski, S.U.; White, M.; Sniehotta, F.F. (2015) Data-prompted interviews: Using individual ecological data to stimulate narratives and explore meanings. Health Psychology. 34 (12), 1191-1194

Lamond, I.R. (Forthcoming). Conceptualising events of dissent: Understanding the Lava Jato rally in Sao Paulo $-5^{\text {th }}$ December 2016. In R. Finkel and Sharp, B. (Eds) Accessibility, Inclusion and Diversity in Critical Event Studies. Abingdon, Routledge. Lamond, I.R.; Spracklen, K. (Eds) (2015) Protests as Events: Politics, Activism and Leisure. London: Rowman \& Littlefield Int.

Live Cinema UK (ND) livecinema.org.uk Retrieved 15 ${ }^{\text {th }}$ March 2018 Mashey, J.R., (1997). October. Big Data and the next wave of infraS-tress. In Computer Science Division Seminar, University of California, Berkeley. Online: https://www.usenix.org/legacy/events/usenix99/invited_talks/mashey.pdf Retrieved $11^{\text {th }}$ November 2017

McGuigan, J. (1996). Culture and the Public Sphere. Abingdon: Routledge.

Moufakkir, O.; Pernecky, T. (Eds) (2014). Ideological, Social and Cultural Aspects or Events. Wallingford: CAB International.

Pachmayer, A.; Andereck, K.; Goodman, R. (2017) Internationalizing the tourism curriculum via study abroad. In P. Benckendorff, A. Zehrer (Eds) Handbook of Teaching and Learning in Tourism pp.336-350

Presence, S. (2013). The political avant-garde: Oppositional documentary in Britain since 1990. Unpublished PhD thesis, University of the West of England.

Richards, V.M. and Lahman, M.K.E. (2015) Photo-elicitation: Reflexivity on method, analysis and graphic portraits. International Journal of Research \& Methods in Education. 38 (1), 3-22

Roche, M. (2017). Mega-events and Social Change: Spectacle, Legacy and Public Culture. Manchester: Manchester University Press. 
Rojek, C. (2013). Event Power: How Global Events Manage and Manipulate. London: Sage.

Solanas, F.; Getino, O. (1969). Hacia un tercer cine (Toward a Third Cinema). Tricontinental 13

Spracklen, K. (2013). Leisure, Sports \& Society. Basingstoke: Palgrave Macmillan.

Spracklen, K.; Lamond, I.R. (2016). Critical Event Studies. Abingdon: Routledge.

Stanley, L. (2012). Rethinking the definition and role of ontology in political science.

Politics, 32(2), 93-99.

Turner, V. (1974) Liminal to liminoid, in play, flow, and ritual: an essay in comparative symbology. Rice Institute Pamphlet-Rice University Studies. 60 (3), 5392

Van Auken, P.M.; Frisvoll, S.J.; Stewart, S.I. (2010) Visualising community: Using participant-driven phot-elicitation for research and application. Local Environment. 15 (4), 373-388

Van Maaker, E. (2000) Integrating ethnographic research and filmmaking: Video elicitation for a performance-orientated analysis of the Teyyam ritual. Visual Anthropology. 13 (2), 185-197

Žižek, S. (2014) Event: Philosophy in Transit. London: Penguin.

Žižek, S. (2016) Disparities. London: Bloomsbury.

Filmography

Lesbians and Gays Support the Miners (LGSM) group, (Producer) Cole, J. (Director). (1986) All Out! Dancing in Dulais. UK, Converse Pictures.

Fletcher, J. (Producer and Director) (2014). Alphabet Club. UK, Jamie Fletcher. Rustemeyer, J.(Producer), Baldwin, G. (Director) (2014). Just Eat It: A Food Waste Story. Canada, Peg Leg Films.

Félez, J.A. (Producer), Manas, A. (Director) (2003). Noviembre. Spain, Alta Films. 
Fano, M. (Producer), Rowland, N. (Director) (2014). Slap. 2014. National Film and Television School.

Christensen, H.E. and Sørensen, S.B. (Producers) Sidibé, A.B.; Siebert, M. and Wagner, E. (Directors). (2016) Les Sauteurs. Denmark, Final Cut for Real. Garthwaite, A. (Producer and Director) (1986) Video 28. UK, Vera Media. Car-Wilson, F. (Producer and Director). (2016) Venus. UK, Northumbria University. Amirani, A. (Producer and Director). (2014) We are Many. UK, Amirani Media. 